\title{
Política de indexação no contexto da política arquivística de preservação digital do Centro de Documentação e Memória da UNESP - CEDEM
}

\author{
Política de indexación en el contexto de la política archivística \\ de preservación digital del Centro de Documentación y Memoria \\ de la UNESP - CEDEM
}

\section{Indexing policy in the context of the digital preservation archival policy of the Documentation and Memory Center of UNESP - CEDEM}

\author{
Mariângela Spotti Lopes Fujita' \\ Sonia Troitiño"
}

\section{Palavras-chave: \\ Política de indexação \\ Política arquivística \\ Preservação digital \\ Movimentos político- -sociais}

\section{Resumo:}

O acesso e recuperação de documentos da memória social brasileira é necessário para comprovar a identidade de movimentos políticosociais brasileiros. Para isso, existe uma logística operacional que envolve estratégias metodológicas da arquivística, da indexação, de interoperabilidade tecnológica e de preservação digital. A união dessas estratégias necessita planejamento mediante elaboração de política de indexação para representação documental com finalidade de precisão e revocação na recuperação. Este trabalho, de característica ensaística, propõe uma abordagem sobre as relações existentes entre as políticas de gestão documental e de indexação com o objetivo de refletir sobre a aplicabilidade da elaboração e implementação da política de indexação no âmbito arquivístico do Centro de Documentação e Memória da Unesp. A análise de uma política de indexação realizou-se com a avaliação do contexto da instituição mediante requisitos para a definição de elementos e variáveis influentes tanto na indexação quanto na recuperação. Entre os resultados destacam-se a necessidade de uso de vocabulário controlado e a sistematização do processo de indexação que propiciarão especificidade e/ou exaustividade. Considera-se que os resultados desta análise ensaística têm inovação porque proporciona visão gerencial à sistemas de recuperação da informação e de recursos informacionais em suporte digital para o contínuo aprimoramento dos métodos e instrumentos de representação documental direcionados ao contexto arquivístico. 


\section{Resumen:}

El acceso y recuperación de documentos de la memoria social brasileña es necesario para comprobar la identidad de movimientos políticosociales brasileños. Para ello, existe una logística operacional que involucra estrategias metodológicas de la archivística, de la indización, de interoperabilidad tecnológica y de preservación digital. La unión de estas estrategias necesita planificación mediante la elaboración de políticas de indización para representación documental con finalidad de precisión y revocación en la recuperación. Este trabajo, de característica ensayística, propone un abordaje sobre las relaciones existentes entre las políticas de gestión documental y de indización con el objetivo de reflexionar sobre la aplicabilidad de la elaboración e implementación de la política de indización en el ámbito archivístico del Centro de Documentación y Memoria de la Unesp (CEDEM) . El análisis de una política de indización se realizó con la evaluación del contexto de la institución mediante requisitos para la definición de elementos y variables influyentes tanto en la indización y en la recuperación. Entre los resultados destacan la necesidad de uso de vocabulario controlado y la sistematización del proceso de indización que propiciarán especificidad y / o exhaustividad. Se considera que los resultados de este análisis ensayístico tienen innovación porque proporciona visión gerencial a los sistemas de recuperación de la información y de recursos informacionales en soporte digital para el continuo perfeccionamiento de los métodos e instrumentos de representación documental dirigidos al contexto archivístico.

\section{Palabras-clave:}

Política de indización

Política archivística

Preservación digital

Los movimientos político-sociales

\section{Keywords:}

Indexing policy

Archival policy

Digital preservation

Political-social movements

\section{Abstract:}

The access and retrieval of documents from the Brazilian social memory is necessary to prove the identity of Brazilian socio-political movements. For this, there is an operational logistics that involves methodological strategies of archival, indexing, technological interoperability and digital preservation. The union of these strategies requires planning through the elaboration of indexing policy for documentary representation with a purpose of precision and recall in the recovery. This work, which is an essay feature, proposes an approach on the relationships between document management and indexing policies, with the objective of reflecting on the applicability of the indexing policy in the archives area of the Documentation and Memory Center of Unesp (CEDEM). The analysis of an indexing policy was carried out with the evaluation of the context of the institution through requirements for the definition of elements and influential variables in both indexation and retrieval. The results highlight the need to use controlled vocabulary and systematization of the indexing process that will provide specificity and / or exhaustivity. It is considered that the results of this essay analysis have innovation because it provides managerial vision to information retrieval systems and digital information resources for the continuous improvement of methods and instruments of document representation directed to the archival context. 


\section{Política de indexação no contexto da política arquivística de preservação digital do Centro de Documentação e Memória da UNESP - CEDEM}

\section{Introdução}

Muito se discute a respeito da necessidade de acesso e recuperação a fundos documentais importantes, preservados em documentos tangíveis, que guardam a memória social brasileira e comprovam a identidade de movimentos político-sociais brasileiros.

A principal característica desses fundos é que são únicos pelo fato de terem sido produzidos por movimentos político-sociais, considerados clandestinos e transgressores em sua época. O acesso e recuperação desses documentos é muito significativo para várias perspectivas, sejam elas históricas, políticas, educacionais, libertárias e etc.

Preservar a memória de movimentos sociais contemporâneos é um dos grandes desafios das instituições de custódia na atualidade. Poucas são as que se aventuram a reunir e conservar arquivos com esse perfil. Isso se deve a uma série de fatores, entre eles destacamos que:

1) Proveniência: Por vezes, a proveniência de um acervo não é de fácil reconhecimento, devido a uma atribulada trajetória custodial - muitas vezes devido a necessidade de salvaguardar os documentos da destruição imposta pelo momento político-social. Como efeito, junções e desmembramentos de documentos são recorrentes em acervos de movimentos sociais, não raramente, afetando a integridade arquivística do fundo;
2) Plano de classificação: Existe uma real dificuldade na classificação desses arquivos devido ao fato das estruturas hierárquicas de movimentos sociais não serem regidas pelas regras do direito administrativo. Em movimentos sociais, a lógica da constituição do grupo e da criação dos registros documentais de suas atividades, não é similar ao de pessoas jurídicas convencionais;

3) Gestão documental: Justamente por não se caracterizarem como instituições tradicionais a gestão de documentos e formação de arquivos sofre prejuízo, considerando que o controle da criação, tramitação e preservação dos registros de atividades de movimentos sociais, não conta com metodologias arquivisticas específicas, desenvolvidas para essa finalidade. Assim, não raramente, assuntos coletivos, referentes aos movimentos, e assuntos particulares, típicos de arquivos pessoais, se mesclam na tentativa de proteção do acervo ou no sentimento de pertencimento despertado pelas fontes.

Entre a instituições de custódia que se voltam para a preservação de acervos com o perfil acima especificado, apresentamos aqui o Centro de documentação e Memória da Universidade Estadual "Júlio de Mesquita Filho" (CEDEM/UNESP) de importância no cenário nacional, o qual tem sob sua responsabilidade acervos únicos e significativos referentes à movimentos político-sociais.

Em geral, em instituições de preservação do patrimônio documental, podemos identificar duas estratégias fundamentais para o acesso a esses fundos documentais: 1) o processo de representação documental por meio da descrição arquivística, que utiliza métodos e instrumentos de indexação para localização e acesso por meio de metadados; e a 2) a digitalização do documento tangível para torná-lo virtual de modo para que possa 
ser preservado e recuperado por qualquer pessoa, independentemente do momento e local onde se encontra, por meio da vinculação do arquivo correspondente a um endereço virtual para consulta.

A união dessas duas estratégias possibilita facilidade de acesso e recuperação, porém, os procedimentos operacionais a serem executados necessitam planejamento mediante discussão de uma política de indexação que preveja o aprimoramento contínuo da representação documental que tenha como finalidade a recuperação com precisão para os usuários.

A definição de uma política de indexação tem início com a avaliação do contexto da instituição mediante requisitos para a definição de elementos e variáveis influentes tanto na indexação quanto na recuperação. Entre esses elementos está o vocabulário controlado e o processo de indexação que propiciarão especificidade e/ou exaustividade. Antes de tudo, é necessário o debate e reflexão sobre a aplicabilidade da indexação e da política de indexação na gestão documental em âmbito arquivístico do Centro de Documentação e Memória da Unesp cuja principal linha de constituição de acervo é a Memória dos movimentos político-sociais brasileiros contemporâneos.

Entretanto, não se pode negar que existe uma logística operacional que envolve estratégias metodológicas da arquivística, da indexação, de interoperabilidade tecnológica e de preservação digital.

Este trabalho, de característica ensaística, propõe uma abordagem sobre as relações existentes entre as diferentes políticas específicas adotadas por arquivos: políticas de preservação, reprodução, tratamento documental e indexação com o objetivo de refletir sobre a aplicabilidade da elaboração e implementação da polí- tica de indexação no âmbito das instituições de memória no Brasil.

Considera-se que os resultados desta análise ensaística têm inovação na medida em que proporciona visão gerencial de sistemas de recuperação da informação e de recursos informacionais em suporte digital para o contínuo aprimoramento dos métodos e instrumentos de representação documental direcionados ao contexto arquivístico.

\section{Política Arquivística e política de indexação, um norte a seguir}

A articulação da Política Arquivística com a política de indexação não é usualmente relacionada, porém, o eixo horizontal de uma política de indexação refere-se às atividades de gestão nas quais as atividades de indexação tem apoio e fundamento. Isso significa que a gestão da política arquivística é o contexto de desenvolvimento e avaliação da política de indexação, ou seja, as variáveis e elementos da indexação são definidos em função do contexto de gestão de cada sistema de organização e recuperação da informação, conforme, explica Fujita (2012, p. 22)

Existem, portanto, duas visões de política de indexação que se complementam: uma visão mais ampliada que considera o contexto da gestão de sistemas de recuperação da informação sobre as atividades de indexação e a visão mais direcionada aos procedimentos e elementos de indexação circunscritos ao manual de indexação, sua operacionalização e avaliação.

Política arquivística em instituições de preservação documental e de memória pode ser entendida como o conjunto de parâmetros, valores e ações voltadas para 
a gestão da instituição, tanto em relação à sua governança, quando ao tratamento do acervo e informações relacionadas. A política arquivística constitui uma política geral, abrangente, que se relaciona com outras mais específicas e direcionadas a importantes questões tangenciais, como são as políticas de acervo, segurança, preservação, indexação, reprodução etc; todas devendo estar articuladas entre si e integradas a um ambiente arquivístico. Dessa forma, nos arquivos, a política pode atingir diversos âmbitos de sua atuação. Por isso, é aconselhável que as instituições de resguardo do patrimônio documental fundamentem suas ações em políticas próprias, por elas mesmas estabelecidas conforme a missão institucional e características do acervo que abrigam, tais como as relativas à preservação, segurança, formação de acervo, acesso ou qualquer outra que oriente protocolos de trabalho. Na prática, este conjunto de medidas se concretiza por meio da adoção de programas que possibilitem a implementação das ações necessárias para sua efetivação.

Para Vásquez Murillo (2015, p. 9495) política arquivística é aquela que formula objetivos e propõe meios apropriados para servir aos direitos e necessidades da sociedade; às instituições produtoras/acumuladoras de documentos; aos interesses individuais ou institucionais, assim como aos pesquisadores. $\mathrm{O}$ autor ainda destaca que a adoção de uma política arquivística não é uma prerrogativa exclusiva do Estado, sendo igualmente passível de ser formulada por entidades de qualquer natureza ou origem. Contudo, alerta que esta não constitui regra imutável, mas antes uma ferramenta adaptável às contingências e necessidades do momento. Sousa (2006) apresenta posição similar, ao defender que os objetivos de uma política pública de arquivo devem ser pautados no direito do cidadão à informação, no apoio administrativo, na proteção da memória e no desenvolvimento científico.
Por sua vez, Fuster Ruiz (1995) considera que as bases de qualquer política arquivística devem se firmar na preservação e utilização dos documentos de arquivo. Para o autor, a melhor medida de segurança do documento e de seu conteúdo se dá por meio da duplicação, através da migração da informação de seu suporte original a outros, mais seguros e cômodos para utilização e guarda do original sob condições adequadas de conservação, fornecendo recursos propícios para a sua longevidade. Dessa forma, acredita que a política de reprodução de documentos seja um ponto fundamental dentro da programação de qualquer política arquivística geral pelas razões que elenca:

1) Seguridad de los originales, preservándolos de todo riesgo de desaparición o destrucción (incendio, inundación, humedad, animales bibliofágos, envejecimiento por el tiempo), y caso de que ello se produzca, dejar a salvo la información que los documentos originales contenían.

2) Modificar la operación de consulta, sin arriesgar los documentos originales, protegiéndolos del deterioro o desaparición.

3) Demanda científica de envío de información a distancia, facilitando la consulta de la información desde centros diferentes a aquél en el que están depositados los documentos originales.

4) Demanda cada vez mayor de reproducción documental.

5) Demandas culturales de divulgación ilimitada de la información.

6) Evidentes repercusiones beneficiosas en la investigación y en la educación. (FUSTER RUIZ,1995, p. 315)

A estas razões unem-se o fato de os programas de reprodução de documentos contribuírem para a difusão, ampliação 
de acesso e disseminação de documentos por meio da Tecnologia da Informação e Comunicação (TIC), além de possibilitar o intercâmbio de acervos documentais e de seus instrumentos de pesquisa através de redes informatizadas (CONSELHO NACIONAL DE ARQUIVOS, 2010). Como vantagem, a política de reprodução apresenta uma evidente economia financeira e social, ao proporcionar acesso ilimitado sem incorrer no desgaste dos originais e consequente aumento do custo de manutenção de sua estabilidade física.

Assim, a adoção de uma política de reprodução de documentos em instituições de preservação documental pode ser entendida como uma real democratização do direito à informação, que permite a consulta ao acervo, mesmo não sendo a consulta feita a originais, mas sim a reproduções. Para isso, a reprodução de originais deve seguir obrigatoriamente protocolos bem estabelecidos, embasados em parâmetros e convenções arquivísticas. Sem seguir essas regras, surge o risco de perda da evidenciação de significativas informações orgânicas e contextuais inerentes aos documentos de arquivo.

Em 2010, o Conselho Nacional de Arquivos (CONARQ), publica a Resolução $n^{\circ} 31$, que "Dispõe sobre a adoção das recomendações para digitalização de documentos arquivísticos permanentes" (CONSELHO NACIONAL DE ARQUIVOS, 2010), recomendando aos órgãos e entidades do Sistema Nacional de Arquivos (SINAR) a adoção das práticas propostas. Esta recomendação, considera a digitalização de documentos de valor permanente uma das tecnologias da informação e comunicação aplicadas aos arquivos, a fim de garantir aos cidadãos o cumprimento do direito de acesso e disseminação de conteúdos. Colabora com os membros do SINAR ao orientar detalhadamente os procedimentos e parâmetros técnicos a serem empregados em projetos de digitalização de acervos de valor permanente.

$\mathrm{Na}$ prática, apesar destas recomendações se destinarem aos arquivos vinculados ao sistema de informação federal, a publicação serviu e ainda serve de referência às instituições de memória, nas mais diferentes esperas do poder público e privado. Entre elas, o CEDEM da UNESP, estudo de caso que abordaremos mais adiante.

Desde 2005, unidades de informação vinham utilizando o formato Portable Document Format/Archive (PDF/A) em seus programas de criação e/ou reprodução de documentos arquivísticos, com base no determinado pela Norma ISO 19005 (INTERNATIONAL STANDARD ORGANIZATION, 2005). A fim de consolidar a utilização do formato PDF/A e elucidar algumas dúvidas relativas ao seu emprego, em 2016, a Câmara Técnica de Documentos Eletrônicos (CTDE) do CONARQ lança a Orientação Técnica $n^{\circ} 4$ Recomendações de uso do PDF/A para Documentos Arquivísticos (CONSELHO NACIONAL DE ARQUIVOS, 2016), com o objetivo de normatizar o uso deste formato para a preservação e acesso de documentos Arquivísticos. A vantagem do uso do PDF/A está na utilização de um formato digital desenvolvido especificamente para a preservação de documentos digitais em longo prazo que atende tanto à produção dos documentos textuais, quanto imagéticos paginados, o que permite manter sua forma fixa e conteúdo estável (CONSELHO NACIONAL DE ARQUIVOS, 2016).

A preservação digital mediante reprodução tem a grande vantagem da democratização do acesso à informação que permite o acesso a qualquer tempo por qualquer usuário. Contudo, a reprodução digital implica armazenagem organizada que possibilite, além da preservação, a recuperação da informação e acesso ao 
formato digital. O documento ou conjunto documental, além de reproduzido digitalmente, precisa ter um registro em formulário digital composto de campos que obedecem aos padrões e formatos internacionais para preenchimento de modo sistemático e uniforme dos dados de identificação física e temática.

Em Arquivística os padrões são a Norma Internacional ISAD(G): General International Standard Archival Description (CONSELHO INTERNACIONAL DE ARQUIVOS, 2000) e a Norma Brasileira de Descrição Arquivística (NOBRADE) (CONSELHO NACIONAL DE ARQUIVOS, 2006). Além dessas normas de padrões para descrição arquivística, a Norma ISO 15489 - Informação e Documentos - Gestão de Documentos (INTERNATIONAL STANDARD ORGANIZATION, 2001, p.4), mais abrangente porque dedicada à implantação do sistema de gestão de documental e inclusão de decisões sobre produção documental, incorporação, controle, arquivamento e acesso, indica a necessidade da elaboração e uso de um tesauro para controle de vocabulário e um dispositivo para criação ou retenção de registros de descrição arquivística e de autoridade em ambiente digital.

Esse processo de armazenagem e organização da informação, seja físico ou virtual, obedece a um ciclo que se inicia pela coleta ou produção documental, passa pelo tratamento documental, como etapa intermediária e determinante da próxima e última etapa, a difusão documental. $\mathrm{Na}$ perspectiva de um ciclo documental, a etapa de tratamento produz informação documentária como resultado da "[...] produção de formas de apresentação e de representação da obra, assim como de seus pontos de acesso em sistemas de informação documentária." (ORTEGA, 2008, p.8). As informações documentárias, portanto, são "[...] apreendidas, registradas e armazenadas em sistemas de informação documentária a fim de que sejam passíveis de recuperação e uso." (ORTEGA, 2008, p.8). Entretanto, para que essa informação documentária seja armazenada e recuperada, precisa ter descrição física e de conteúdo. Segundo, Brascher e Café (2008, p. 5), "A organização da informação é um processo que envolve a descrição física e de conteúdo dos objetos informacionais.".

Tal como foram desenvolvidos os conhecimentos relativos à descrição física e a descrição de conteúdo, verificamos que o resultado desses processos de organização da informação são representações da informação, a informação documentária.

A representação da informação refere-se aos dados de descrição física (autoria, título e tipo do documento e dados de produção que inclui local, produtor e ano) e de descrição temática (termos que representam os assuntos do conteúdo). Cada um desses itens da descrição serve como ponto de acesso. O ponto de acesso direciona o usuário para o registro completo de descrição física e temática; o registro possibilita ao usuário decidir se o objeto informacional interessa ou não; e a localização encaminha o usuário para o documento digital desejado. Atualmente, os registros de descrição física e temática necessitam de sistemas de informação que utilizem softwares com possibilidade de compartilhamento para interoperabilidade entre outros sistemas o que poderá facilitar a armazenagem tanto dos documentos digitais quanto dos registros.

Mas, existe uma distinção importante entre a descrição física e a de conteúdo: enquanto a descrição física, realizada por meio da catalogação, refere-se a aspectos físicos de objetos informacionais, a descrição de conteúdo, realizada por meio da indexação, trabalha com conceitos. A descrição física produz represen- 
tação física da informação e a descrição de conteúdo a representação conceitual da informação. Ambos os produtos de descrição física e temática compartilham um mesmo registro de descrição ou metadados em campos distintos de modo que podem funcionar como pontos de acesso em um processo de busca pelo usuário. Assim como, é possível incluir no metadados o link ou endereço eletrônico para o documento digital.

O resultado da indexação é, portanto, uma representação do conteúdo do documento para sua acessibilidade temática por assunto. A indexação é um processo, resumidamente, realizado em duas etapas essenciais: a análise e a representação. $\mathrm{Na}$ etapa de análise é feita a identificação e seleção de conceitos que representarão o conteúdo significativo do conteúdo e, na etapa de representação, os conceitos selecionados passarão por controle de vocabulário com uso de linguagens de indexação ou vocabulários controlados com a finalidade de adequação ao vocabulário do usuário. Conforme Barité, et al. (2015, p.87), indexação é

A operação mais significativa da análise documental que se refere ao processo de descrição e representação do conteúdo temático de um documento, por meio de um número limitado de termos obtidos diretamente do texto dos documentos (palavras-chave) ou vocabulários controlados (descritores ou cabeçalhos de assunto). Esses termos devem ser aqueles que mais apropriadamente caracterizam o documento, a fim de facilitar sua futura recuperação temática.

Na etapa de representação é fundamental o uso de vocabulários controlados ou linguagens de indexação. Com o objetivo de representar o conteúdo documental para a recuperação, a indexação, enquanto processo, não poderá estar dissociada da gestão documental e, principalmente, do sistema de informação. Para isso, precisa ser moldada e adequada ao contexto de produção documental por seus atores principais atuantes no tratamento e na recuperação, o profissional arquivista e o usuário. Isso porque, ao ser realizado, o processo de indexação é influenciado por requisitos, elementos e variáveis previamente definidos em função de cada contexto em que se localiza o sistema de informação (CARNEIRO, 1985).

Os requisitos, relacionados às atividades de gestão (plano horizontal), são a instituição, a clientela e os recursos financeiros, materiais e humanos, ou seja, o ambiente em que se insere o sistema de informação.

Os elementos, relacionados às atividades de organização e representação da informação, são sete: cobertura de assuntos, seleção e aquisição de documentos-fonte, processo de indexação, estratégia de busca, tempo de resposta do sistema, forma de saída e avaliação do sistema.

O processo de indexação é o elemento essencial da política e determinante dos resultados de recuperação da informação. Segundo Carneiro (1985), o processo de indexação é afetado diretamente por um conjunto de variáveis influentes na representação (durante a indexação) e, consequentemente, na recuperação da informação (resultado da indexação): exaustividade, especificidade, escolha da linguagem de indexação, revocação e precisão.

O conjunto de requisitos, elementos e variáveis da política de indexação do CEDEM serão analisados para estudo de uma proposta de articulação à política arquivística de armazenagem e organização da reprodução digital da memória de movimentos político-sociais. 


\section{CEDEM: Memória, Movimentos Sociais e seu local de guarda}

O CEDEM é um centro que se destaca por seu caráter interdisciplinar, mantido pela conjugação das áreas de Ciências Humanas, Letras e Artes, Ciências Sociais Aplicadas e demais Ciências afins ficando estabelecidas as especialidades do CEDEM a partir da definição de linhas de pesquisas orientadoras de seus projetos. Dessa forma, o CEDEM tem por objetivos: 1) Preservar e difundir a Memória da Universidade; 2) Preservar e difundir a memória social no âmbito da competência da Universidade; 3) Realizar pesquisas de caráter acadêmico cujos temas estejam relacionados com as áreas do conhecimento com as quais o CEDEM mantém diálogo permanente e que digam respeito à sua área de atuação; 4) Promover atividades de extensão; 5) Interagir com o ensino em todos os seus níveis.

Com essa proposta, o CEDEM assume como missão institucional a preservação, pesquisa e difusão de documentos e informações sobre memória universitária e movimentos sociais, especialmente os de caráter político contemporâneo brasileiro, bem como de outras fontes produzidas no âmbito da missão da Universidade, em suas dimensões de ensino, pesquisa e extensão.

Em 1987, um grupo de docentes interessados na preservação de documentos e formação da memória histórica da Unesp elaborou um projeto de criação de um centro de documentação e memória para a universidade. Surgia o Cedem, em larga medida, moldado a partir da idealização de um núcleo de memória universitária, mas também, naquela ocasião, com a ideia de se constituir núcleos específicos sobre a memória paulista e sobre documentação regional (UNIVERSIDADE ESTADUAL PAULISTA JÚLIO DE MESQUITA FILHO, 1987).
Da concepção à concretização, ajustes ao projeto inicial fizeram-se necessários, e os núcleos sobre memória paulista e documentação, posteriormente, deram lugar a acervos sobre a memória de movimentos sociais. Processo iniciado em 1994, com a entrada da totalidade de acervos de outras instituições, como a do Archivio Storico del Movimento Operaio Brasiliano (ASMOB/IAP) e do Centro de Documentação do Movimento Operário Mario Pedrosa (CEMAP), por meio de convênio estabelecido. A partir desse momento, o CEDEM começa a acolher arquivos sobre movimentos sociais de diversas origens e condições jurídicas - doação, depósito, compra (CAMARGO, 2008).

Desde então, o CEDEM passou a reunir fontes preciosas para o conhecimento da história contemporânea do Brasil. Ao receber esses fundos documentais, se tornou responsável técnica e legalmente por sua integridade, organização arquivística e disponibilização de seus conteúdos. Segundo política do centro, o recolhimento desses documentos, além de representar o cumprimento de um compromisso da universidade para com a sociedade, é também uma maneira de a valorizar ao proporcionar aos seus pesquisadores o acesso a fontes documentais até então não disponíveis ou de difícil acesso (CENTRO DE DOCUMENTAÇÃO E MEMÓRIA DA UNESP, 2015).

Dessa forma, o CEDEM desenvolve suas atividades a partir da constituição e desenvolvimento de duas linhas fundamentais de acervo: Memória Universitária e Memória dos Movimentos Político-Sociais Brasileiros Contemporâneos. Hoje em dia, sob sua responsabilidade existem importantes arquivos e coleções, destacando-se por abordar temáticas relacionadas ao processo político do país, à memória social e à preservação do patrimônio histórico e de bens culturais ao abrigar coleções e arquivos produzidos ou acumu- 
lados por pessoas, organizações, partidos políticos e demais entidades, identificadas como formadores e integrantes das esquerdas brasileiras.

O CEDEM, talvez por custodiar documentos provenientes de movimentos sociais com caráter político - muitas vezes reunidos na clandestinidade, perdidos e recuperados diversas vezes, com passagem por vários titulares, apresentando elevado grau de dificuldade na identificação da proveniência e ordem original em geral trata tais documentos de forma articulada, entre fundos e coleções, agrupados fisicamente por critérios variados, como espécie ou gênero documental (periódicos, cartazes, fotografias, livros, documentos textuais, audiovisual). Contudo, a informação sobre a procedência sempre é preservada na descrição ou base de dados correspondente, assim como descritores relativos às unidades ou itens documentais. Ainda que não utilize o modelo de sistema de séries elaborado por Scott (1966), certas opções metodológicas às vezes podem lembrar, mesmo que vagamente, as propostas do autor.

\section{Política arquivística de preservação digital e o tratamento documental no Sistema de Gestão de Acervos Permanentes da Unesp (SisAcervo)}

Programas de reprodução de acervo, ao longo das três décadas de atuação do CEDEM, sempre ocuparam uma posição central no planejamento estratégico da instituição. Experiências nessa área remontam ao final dos anos 90 , quando se une à equipe técnica do centro uma programadora, que mais tarde, ao sair desenvolve o software Alexandria, que inclusive foi posteriormente adquirido pelo CEDEM para descrever arquivisticamente o acervo. Nesse momento, não havia o conjunto de normas que hoje embasam os trabalhos de insti- tuições arquivísticas, a exceção das incipientes ISADg e ISAARcpf. Contudo, essas primeiras versões das normas, não foram adotadas pelo Alexandria.

Com o passar dos anos e a necessidade de alinhamento às normas nacionais e internacionais em vigor, aliado à resolução Unesp que determina que todos os sistemas institucionais devem ser produzidos pela própria universidade, tem início o desenvolvimento de um sistema novo com recursos próprios da universidade, estruturado sobre diretrizes do Conselho Internacional de Arquivos e do Conselho Nacional de Arquivos (CENTRO DE DOCUMENTAÇÃO E MEMÓRIA DA UNESP, 2017). Surge, então, o Sistema de Gestão de Acervos Permanentes da Unesp (SisAcervo), instrumento institucional para a descrição arquivística dos acervos da Universidade.

Os documentos do acervo do CEDEM estão representados (catalogados e indexados) neste sistema, que está disponível à consulta pública a partir da página

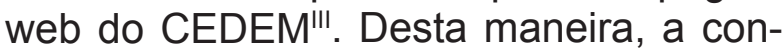
sulta às referências de fundos e coleções abrigados pelo CEDEM, encontram-se disponíveis online. Documentos já digitalizados são inseridos no sistema, conectando-se a referência que lhe corresponde. Esse processo e upload do objeto digital, localização da referência correspondente e vinculação entre ambos, é trabalho moroso e imprescindível; e passa por diversas revisões a fim de minimizar possibilidades de falhas.

São esperados como produtos da implementação do SisAcervo: 1) Garantia da conservação física dos documentos tratados; 2) Representação da informação documentária (catalogação e indexação) e conservação do acervo, na medida que os documentos convertidos a formato digital são inseridos no SisAcervo, o que obrigatoriamente impinge a inserção de metadados arquivísticos que possibilitem a 
recuperação de informações, conforme os parâmetros de busca eleitos pelo usuário; e 3) Disponibilização e difusão do acervo digitalizado à consulta pública e irrestrita.

A produção destes produtos corrobora com as orientações apresentadas por Fuster Ruiz (1995) e Recomendações para digitalização de documentos arquivísticos permanentes. (CONSELHO NACIONAL DE ARQUIVOS, 2010)

O SisAcervo - Sistema de Gestão de Acervos Permanente foi desenvolvido como banco de dados para a atividade de descrição arquivística conforme a NOBRADE. Disponibiliza as informações sobre seu acervo em rede interna e na web, em sítio próprio, por meio de um catálogo online que centraliza informações relativas a todos os fundos e as coleções abrigados pelo CEDEM.
O sistema, além de permitir catalogação e pesquisa, possui uma administração da entrada de fundos e coleções no acervo e um módulo de Serviços destinado à administração dos usuários e das pesquisas realizadas, gerando estatísticas de consultas, tipos de pesquisas e principais conjuntos documentais pesquisados como ferramenta de planejamento e controle administrativo institucional (CENTRO DE DOCUMENTAÇÃO E MEMÓRIA DA UNESP, s/d).

Para melhor exemplificar o processo de integração entre os programas de reprodução de documentos e indexação, ao confluírem no SisAcervo, tomemos como exemplo o documento ¡Alto a la represión y las torturas!, um dos documentos iconográficos mais emblemáticos da coleção de cartazes, sob tutela do CEDEM.

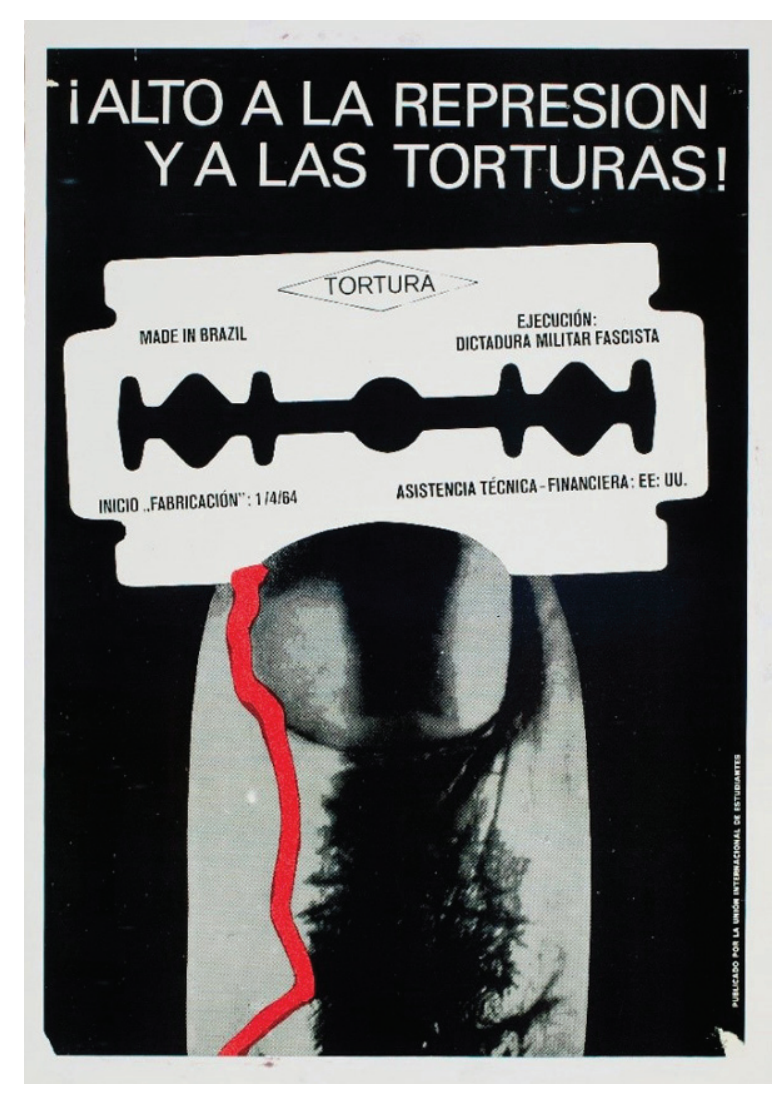

Figura 1 - Cartaz Alto a la represión y a las torturas!

Fonte: Unión Internacional de Estudiantes. ¡Alto a la represión y a las torturas! Cartaz. CEDEM. Acervo ASMOB, s/d. 
É preciso considerar que em um arquivo, ainda que este possua um programa de reprodução de documentos, não é aconselhável a duplicação total do acervo. Devem ser definidos previamente os critérios utilizados para selecionar os documentos apropriados para serem duplicados, relacionando-os aos motivos e condições necessários para a reprodução preventiva e de acesso. Entre eles, é possível elencar algumas das razões recorrentes, como: grande demanda de consulta, fragilidade do suporte e acentuado interesse social. Contudo, aos motivos que levam a iniciativa de reproduzir determinado documento ou conjunto documental, se une a verificação das condições físicas e técnicas relacionadas. Assim, devem ser verificadas, individualmente e em conjunto, as características físicas do documento (dimensões, gramaturas, materiais utilizados, etc.), nível de deterioração do suporte, técnicas empregadas para a fixação da informação e estado de conservação geral (qualidade da tinta, gravação, tipo de escrita, etc.).

A combinação destes elementos tem peso decisivo na eleição dos segmentos a serem duplicados e das técnicas escolhidas para a mudança do suporte da informação. Em outras palavras, o desgaste provocado pelo processo de captura da imagem documental é determinante para a escolha do procedimento técnico a ser utilizado para a mesma. Dessa maneira, o cartaz ¡Alto a la represión y las torturas!, apresentava as condições necessárias para sua digitalização, sendo esta realizada por meio de técnica fotográfica, devido as grandes dimensões físicas do original.

Entretanto, duplicar o documento, mantendo sua versão original em formato convencional e a versão duplicada, em formato digital, não é suficiente para fornecer acesso aos pesquisadores. A descrição do documento é uma das funções primordiais de qualquer arquivo, pois através da representação do documento é possível recuperar informações e localizar originais em meio a uma infinidade de registros.
No SisAcervo, a descrição documental é realizada durante o cadastramento de documentos, seguindo critérios da NOBRADE, como já exposto anteriormente. $O$ módulo Cadastramento, restrito à equipe técnica autorizada, permite inserção e/ou alteração dos dados relativos ao acervo descrito. Para tanto, foram definidos campos descritivos divididos por áreas, conforme as especificidades necessárias para a contextualização arquivística dos documentos.

Estas planilhas descritivas foram formatadas para a inserção de metadados arquivísticos, compondo um sistema estruturado por formulários de preenchimento específico para cada tipo de acervo e por módulos de consulta interna e externa online. Assim, o sistema foi programado para agrupar os gêneros e suportes documentais do acervo, por meio de campos e tabelas auxiliares, que possibilitam a pesquisa simples e/ou combinada com a totalidade do acervo, a saber: Autorias; Títulos; Descritores; Editoras; Idiomas; Localidades; e Plano de Classificação.

As planilhas descritivas (fichas catalográficas) desenvolvidas são compostas por campos definidos em respeito às particularidades dos documentos pertencentes a determinados gêneros e espécies documentais: Audiovisuais; Sonoros; Cartazes; Fotografias; Documentos textuais; Dossiês temáticos; Livros; Periódicos; Clippings e Objetos. O layout das planilhas foi definido considerando o registro de dois tipos de dados - os comuns e os específicos. Para os comuns, constam os campos a serem preenchidos: Identificação ou Tema ou Título; Data; Localização Física/Microfilme/Digital; Local de produção; Autorias; Descritores; Classificação; Descrição; e Notas. Já, para os dados específicos, as planilhas apresentam campos necessários ao detalhamento descritivo dos suportes em questão e, também, para o registro de informações específicas dos documentos (CENTRO DE DOCUMENTAÇÃO E MEMÓRIA DA UNESP, 2013). 
Entre as diversas abas descritivas, destacamos "Objeto Digital" e "Área Temática". Objeto digital é a aba que possibilita o upload da imagem capturada, permitindo que o pesquisador tenha acesso ao documento digitalizado por meio do sistema disponível na web.

As informações contidas na aba Área Temática corroboram justamente para a recuperação desses objetos e possuem intima relação com o processo de indexação do documento. Este pode ser considerado o ponto de encontro entre dois programas fundamentais: o programa de organização arquivística do acervo e o programa de reprodução de originais levados a cabo pelo CEDEM nas últimas décadas. Assim, é realizado o upload dos arquivos digitais diretamente nos formulários de registro do sistema informatizado de descrição arquivística, visando a disponibilização de uma cópia dos originais à consulta pública.

Para o cartaz ¡Alto a la represión y las torturas! foram definidos os descritores: Brasil; Regime Militar; Tortura; Exílio. Termos escolhidos não apenas a partir da interpretação textual literal, mas também com base em informações contextuais, relativas à produção e acumulação do documento. Por exemplo, o termo "exílio". Não consta menção a palavra exílio no discurso disposto no documento. Porém, ao ser descrita no sistema, o indexador levou em consideração que o documento original pertence ao acervo do $A S M O B$, mais especificamente a uma coleção que, em sua formação de origem, foi batizada de Coleção Exílio (hoje Coleção do ASMOB) por reunir documentos que circulavam entre os exilados brasileiros durante os anos 1960 e 1970 ou fruto de campanhas políticas realizadas desde o exílio para denunciar a perseguição política vivida no Brasil, naquele período.

Este entendimento é reforçado ao verificar o campo "descrição", na aba "Área de Identificação", onde consta o seguinte conteúdo: "Denúncia de tortura no Regime Mili- tar Brasileiro. Forma - Desenho". Assim, nos parece bastante significativo que a descrição e indexação de documentos, no CEDEM, extrapolem análise documentária e tendam a interpretação arquivística, sempre contextual, e histórica do objeto representado.

A determinação de assuntos dos documentos é realizada conforme o seguinte relato descritivo fornecido por profissional que atua no CEDEM:

Lêem o conteúdo e definem uma palavra que acreditam que correspondem. Algumas, provavelmente por hábito, outras são palavras recorrentes nos documentos e/ou no discurso do movimento/historiografia. Ex: exílio, tortura, comunismo, anistia. Mas realmente, é um processo individual, autônomo. Aliás, todo o processo de descrição é assim. Pode ser que existam campos (metadados) pré-definidos, o que regula sim um pouco o processo de descrição, mas não existem regras definidas para como preencher o conteúdo desses campos. O que todos relatam é que depende. Ao que parece, o próprio documento determina como ser representado. Entre os técnicos também não há concordância, cada um resguarda o seu "direito" a fazer como acredita ser certo.

O uso de vocabulário controlado é relatado abaixo:

Houve tentativa de construção de vocabulário, mas não se desenvolveu. Atualmente utilizamos linguagem natural. O sistema permite a todos que cadastram documentos incluírem quantos termos quiserem para indexar. O que significa que um documento pode ter apenas um termo ou 10 que o representem. O indexador pode incluir na tabela geral do sistema quantos termos quiser, livremente. Na hora que o indexador pede para cadastrar um novo termo, deve escolher o "tipo de descritor": Temático, geográfico ou onomástico. Ele pode, inclusive, alterar os termos já cadastrados, tanto em relação ao nome, quanto ao tipo. Por exemplo: 


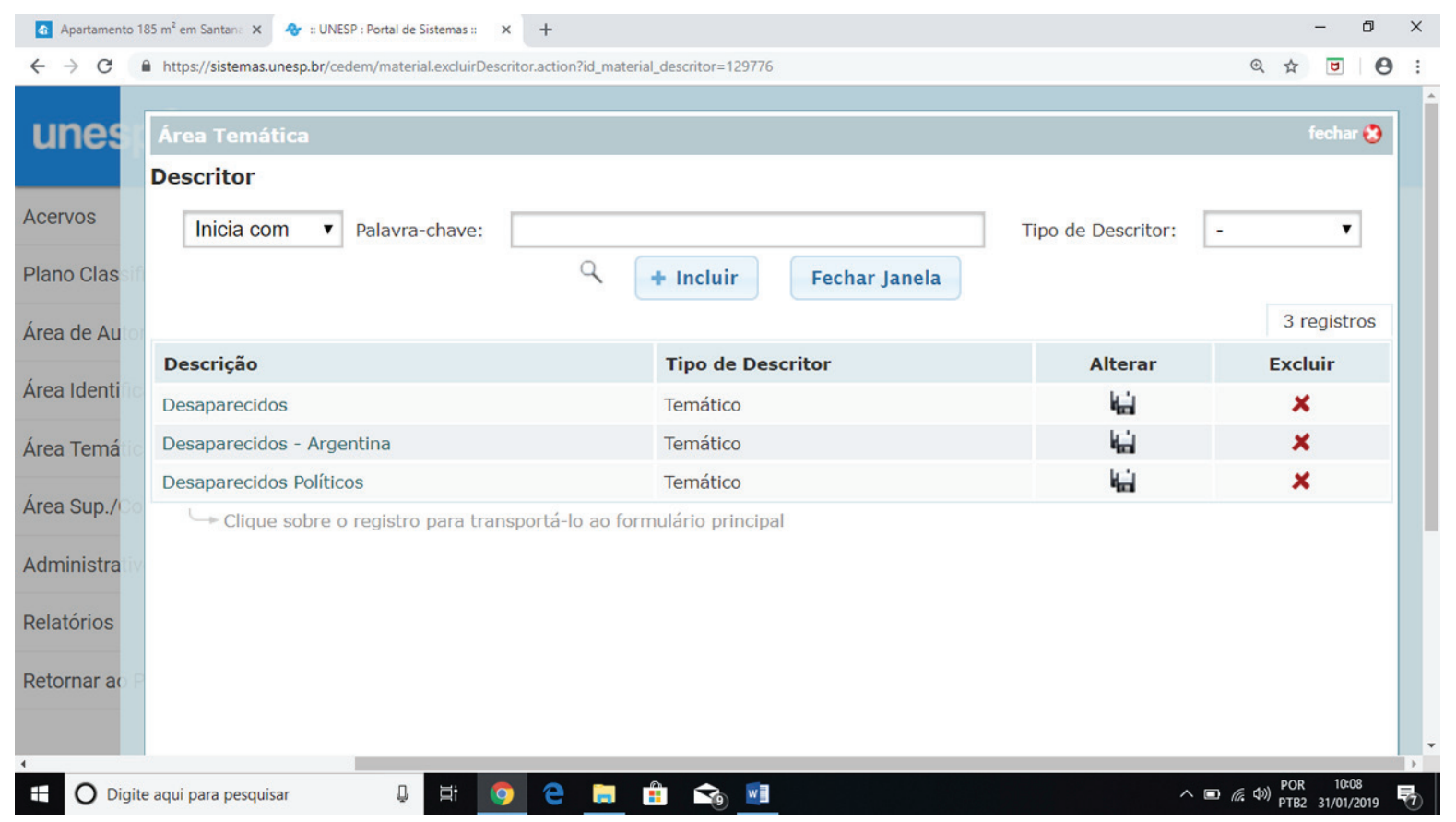

Figura 2 - Tela da área temática para escolha do tipo de descritor Fonte: Catálogo online do CEDEM

Outro módulo importante do SisAcervo é o Pesquisa no Banco de Dados, disponível aos usuários a partir da página web da instituição. Este módulo permite ao a pesquisa em dois níveis distintos: 1) simples por títulos, autorias e descritores; 2) combinada por títulos, autorias, locais, editoras, notas, descritores e instituições. Ainda, há um outro tipo de pesquisa filtrada por fundo ou coleção documental e período.

\section{Análise da política de indexação do CEDEM: proposta de articulação à política arquivística digital dos movimentos político-sociais brasileiros contemporâneos}

A representação por assunto é tarefa da indexação e dos seus instrumentos de representação, as linguagens de indexação e vocabulários controlados. Entretanto, a aplicação da indexação e seus instrumentos à política arquivística necessita de articulação mediante elaboração de uma política de indexação tendo em vista a diversidade de requisitos, elementos e variáveis em contexto arquivístico.
Com a proposta de realizar estudo ensaístico sobre as relações existentes entre as diferentes políticas adotadas por arquivos serão analisados, a partir do contexto da política arquivística do CEDEM, o conjunto de requisitos, elementos e variáveis da política de indexação para uma proposta de articulação à política arquivística de armazenagem e organização da reprodução digital da memória de movimentos político-sociais. Para isso, utilizaremos a sequência de análise do estudo ensaístico de Fujita e Troitiño (2018, p.105-13) para arquivos de instituições de saúde com base no relato da política arquivística do CEDEM que consta no item 4.

A sequência de análise consta de dois planos e 3 aspectos: os requisitos no plano horizontal representa as atividades de gestão arquivística, os elementos e as variáveis no plano vertical representam as atividades de organização e representação da informação.

No plano horizontal o conjunto de requisitos correspondem às condições de 
funcionamento do sistema de informação a partir da identificação da organização, clientela, recursos financeiros, materiais e humanos, cuja análise será relevante para a definição do serviço a ser oferecido e, ao mesmo tempo, influenciará o funcionamento do plano vertical nos produtos e serviços a serem oferecidos ao usuário do sistema de informação (CARNEIRO, 1985).

Por isso, será necessário que o CEDEM desenvolva diferentes estudos para conhecimento de seus requisitos: perfil e vocabulário de domínio de seus usuários e a política institucional da Universidade para a estrutura física, financeira, material e humana do CEDEM. O resultado desses estudos, principalmente o de usuário, servirão de base para a definição e/ou aprimoramento dos elementos e variáveis da política de indexação no plano vertical. Por outro lado, é preciso identificar na estrutura de recursos humanos quem participa diretamente da implementação da política de indexação. Com certeza, os mesmos que atuam no desenvolvimento e alimentação do SisAcervo.

O Sistema de Gestão de Acervos Permanentes é o resultado concreto de uma política arquivística que levou em consideração todos os requisitos do plano horizontal na elaboração e implantação, mesmo que a documentação descritiva dos estudos realizados seja um conjunto de especificações técnicas (CENTRO DE DOCUMENTAÇÃO E MEMÓRIA DA UNESP, s/d) e um manual de operações do módulo de cadastramento. Dessa forma, podemos considerar o SisAcervo como o resultado da elaboração e implementação, não só de uma política arquivística, como também, de política de indexação. Interessante seria elaborar um Manual do Sistema com a descrição pormenorizada de todas as especificações do SisAcervo relacionadas à política arquivística e à política de indexação. Não restam dúvidas de que é necessário registrar a memória do sistema de informação, em cada pormenor, para facilitar futuros aprimoramentos, como também, seu uso uniforme por diferentes utilizadores atuando em tempos diferentes.

Porém, ainda assim, seria fundamental realizar estudo do perfil e das necessidades de informação de sua comunidade de usuários, tendo em vista que é desconhecido o vocabulário utilizado para pesquisas. Seria muito sugestivo realizar avaliações contínuas acerca dos termos utilizados para busca de informações no SisAcervo.

Ficou claro, também, que o CEDEM segue os marcos regulatórios produzidos no âmbito da Universidade e por instituições normalizadoras em âmbito brasileiro e internacional, como por exemplo, o metadados para registro das descrições físicas e temáticas obedece aos parâmetros estabelecidos pela NOBRADE e a reprodução digital dos documentos obedece a orientação técnica do CONARQ. Além disso, o CEDEM tem política arquivística descrita nos seguintes documentos: relatório de gestão (CENTRO DE DOCUMENTAÇÃO E MEMÓRIA DA UNESP, 2017), Política de desenvolvimento de coleções (CENTRO DE DOCUMENTAÇÃO E MEMÓRIA DA UNESP, 2015) e guia de acervo (CAMARGO, 2008). Seria importante reunir todas as informações sobre o CEDEM e suas diversas políticas, seja arquivística, de preservação, reprodução, tratamento documental, desenvolvimento de coleções e de indexação, em documento único que pudesse demonstrar o entrelaçamento de todas as suas políticas.

A política de informação necessita, principalmente, de padronização de registros e de padronização do arquivamento eletrônico combinado com a indexação e uso de vocabulário controlado. Nesse sentido, vamos analisar, na sequência, o plano vertical composto de elementos e variáveis da política de indexação. Os elementos elencados por Carneiro (1985, p.231), bem como a função e aplicação de cada um na perspectiva do CEDEM, podem ser compreendidas no Quadro 1: 


\begin{tabular}{|c|c|c|}
\hline Elementos & Função & Aplicação ao CEDEM \\
\hline $\begin{array}{l}\text { 1. Cobertura } \\
\text { de assuntos: }\end{array}$ & $\begin{array}{l}\text { assuntos cobertos } \\
\text { pelo sistema } \\
\text { (centrais e periféricos); }\end{array}$ & $\begin{array}{l}\text { Definir com exatidão os assuntos gerais das coleções e } \\
\text { definir grandes áreas e suas áreas subordinadas para } \\
\text { facilitar a indexação; }\end{array}$ \\
\hline $\begin{array}{l}\text { 2. Seleção } \\
\text { e aquisição } \\
\text { dos } \\
\text { documentos- } \\
\text { fonte: }\end{array}$ & $\begin{array}{l}\text { extensão da cobertura } \\
\text { do sistema em áreas } \\
\text { de assunto } \\
\text { e a qualidade } \\
\text { dos documentos } \\
\text { incluídos no sistema; }\end{array}$ & $\begin{array}{l}\text { Observar a política de desenvolvimento de coleções e incluir } \\
\text { item específico sobre prioridades de preservação digital das } \\
\text { coleções documentais; levando-se em consideração a } \\
\text { evolução tecnológica deve-se preocupar com a qualidade de } \\
\text { documentos reproduzidos digitalmente, apoiando-se em } \\
\text { normas nacionais e internacionais, o que já foi providenciado } \\
\text { pelo CEDEM quando da reprodução digital de suas coleções; }\end{array}$ \\
\hline $\begin{array}{l}\text { 3. Processo } \\
\text { de indexação: }\end{array}$ & $\begin{array}{l}\text { desenvolve-se pela } \\
\text { análise, síntese e } \\
\text { representação e é } \\
\text { influenciado pelas } \\
\text { variáveis exaustividade, } \\
\text { especificidade, escolha } \\
\text { da linguagem e } \\
\text { capacidade de } \\
\text { revocação e precisão } \\
\text { do sistema; }\end{array}$ & $\begin{array}{l}\text { Em um sistema complexo ou simples é possível que o } \\
\text { processo de indexação possa ser realizado por profissionais } \\
\text { da informação capacitados que tenham conhecimento e } \\
\text { acesso à a política de indexação; para isso é preciso que os } \\
\text { procedimentos para indexação estejam disponíveis com suas } \\
\text { orientações e decisões em formato elucidativo para que não } \\
\text { seja difícil realizar a indexação conforme variáveis } \\
\text { estabelecidas; recomenda-se a elaboração de um manual de } \\
\text { indexação com a sistematização de procedimentos; }\end{array}$ \\
\hline $\begin{array}{l}\text { 4. Estratégia } \\
\text { de busca: }\end{array}$ & $\begin{array}{l}\text { deve-se decidir entre } \\
\text { a busca delegada } \\
\text { ou não; }\end{array}$ & $\begin{array}{l}\text { Atualmente é preciso tomar decisões quanto ao software e } \\
\text { sistema de armazenagem digital que permita facilidade de acesso } \\
\text { com segurança e integridade para todos em busca delegada para } \\
\text { usuários à distância; os mecanismos e ferramentas de busca e } \\
\text { acesso precisam ser amigáveis e estar disponíveis na web para } \\
\text { qualquer usuário, seja profissional, técnico ou especialista e leigo; } \\
\text { recomenda-se a aplicação de estudos de avaliação do uso do } \\
\text { software e ferramentas de busca, bem como a disponibilização } \\
\text { da linguagem de indexação ou vocabulário controlado para } \\
\text { consulta do usuário na estratégia de busca; }\end{array}$ \\
\hline $\begin{array}{l}\text { 5. Tempo } \\
\text { de resposta } \\
\text { do sistema: }\end{array}$ & & $\begin{array}{l}\text { É um elemento que atualmente não tem necessidade de ser } \\
\text { considerado pelo acesso simultâneo e imediato dos sistemas de } \\
\text { busca e recuperação da informação disponíveis online na web; }\end{array}$ \\
\hline $\begin{array}{l}\text { 6. Forma } \\
\text { de saída: }\end{array}$ & $\begin{array}{l}\text { é o formato físico } \\
\text { em que os resultados } \\
\text { da busca são } \\
\text { apresentados. }\end{array}$ & $\begin{array}{l}\text { Tem grande influência sobre a tolerância do usuário quanto à } \\
\text { legibilidade e precisão dos resultados. Deve-se verificar qual a } \\
\text { preferência do usuário quanto à apresentação dos resultados e } \\
\text { para isso recomenda-se o desenvolvimento de pesquisas em } \\
\text { design da informação para investigar a usabilidade e arquitetura } \\
\text { da informação em ambiente digital, bem como é necessário a } \\
\text { escolha de formatos de metadados para a inclusão dos dados } \\
\text { que representam tanto a descrição física quanto temática } \\
\text { (descritores da linguagem); recomenda-se ainda estudos de } \\
\text { avaliação contínuos e constantes de recuperação da informação } \\
\text { para aprimoramento do sistema de busca por assunto; }\end{array}$ \\
\hline
\end{tabular}




\begin{tabular}{|l|l|l|}
\hline \multicolumn{1}{|c|}{ Elementos } & \multicolumn{1}{|c|}{ Função } & \multicolumn{1}{c|}{ Aplicação ao CEDEM } \\
\hline $\begin{array}{l}\text { 7. Avaliação } \\
\text { do sistema: }\end{array}$ & $\begin{array}{l}\text { determinará até } \\
\text { que ponto o sistema } \\
\text { satisfaz as } \\
\text { necessidades dos } \\
\text { usuários; }\end{array}$ & $\begin{array}{l}\text { A avaliação é uma etapa da política que deve ser realizada para: } \\
\text { a) analisar os problemas de recuperação do sistema de busca e } \\
\text { verificar as causas; b) verificar ajustes na implementação da } \\
\text { proposta elaborada para a política; c) avaliar futuros } \\
\text { aprimoramentos na implementação da proposta de política de } \\
\text { indexação; recomenda-se ainda a elaboração e experimentação } \\
\text { de metodologia de avaliação com a finalidade de sistematização. }\end{array}$ \\
\hline
\end{tabular}

Quadro 1 - Função e aplicação dos elementos da política de indexação Fonte: Fujita e Troitiño, 2018, p.

As variáveis, segundo Carneiro (1985), que influenciam o processo de indexação e impactam na recuperação da informação, podem ser visualizadas no Quadro 2 acompanhadas da função e da aplicação no CEDEM:

\begin{tabular}{|c|c|c|}
\hline Variáveis & Função & Aplicação no CEDEM \\
\hline $\begin{array}{l}\text { Nivel de } \\
\text { exaustividade: }\end{array}$ & $\begin{array}{l}\text { "[...] uma medida de extensão } \\
\text { em que todos os assuntos } \\
\text { discutidos em um certo } \\
\text { documento são reconhecidos } \\
\text { na operação de indexação e } \\
\text { traduzidos na linguagem do } \\
\text { sistema" (LANCASTER, } 1968 \\
\text { apud CARNEIRO, 1985, p. 232); }\end{array}$ & \multirow{2}{*}{$\begin{array}{l}\text { A especificidade e exaustividade são duas variáveis } \\
\text { que atuam durante o processo de indexação nas } \\
\text { etapas de análise de assunto pelo indexador para } \\
\text { identificação e seleção de conceitos e na tradução } \\
\text { dos conceitos por termos do vocabulário controlado; } \\
\text { a escolha de uma outra variável ou ambas } \\
\text { influenciam de modo determinante a recuperação da } \\
\text { informação que terá maior ou menor precisão, ou, ao } \\
\text { contrário, maior ou menor revocação; o importante } \\
\text { na política de indexação, além de todos os requisitos, } \\
\text { elementos e variáveis, é que o sistema de } \\
\text { informação possa ter o controle dos níveis de } \\
\text { especificidade e exaustividade e isso somente se } \\
\text { consegue com controle de vocabulário e, } \\
\text { principalmente, com estudos de necessidades de } \\
\text { usuários e avaliaçães de recuperação da informação. }\end{array}$} \\
\hline $\begin{array}{l}\text { Nível de } \\
\text { especificidade: }\end{array}$ & $\begin{array}{l}\text { "[...] a extensão em que o } \\
\text { sistema nos permite ser } \\
\text { precisos ao especificarmos o } \\
\text { assunto de um documento que } \\
\text { estejamos processando" } \\
\text { (FOSKET, 1973 apud } \\
\text { CARNEIRO, 1985, p. 232); }\end{array}$ & \\
\hline $\begin{array}{l}\text { Escolha da } \\
\text { linguagem de } \\
\text { indexação ou } \\
\text { do vocabulário } \\
\text { controlado }\end{array}$ & $\begin{array}{l}\text { Afeta o desempenho de um } \\
\text { sistema de recuperação de } \\
\text { informação tanto na estratégia } \\
\text { de busca (estabelece a } \\
\text { precisão com que o técnico de } \\
\text { busca pode descrever os } \\
\text { interesses do usuário) quanto } \\
\text { na indexação (estabelece a } \\
\text { precisão com que o indexador } \\
\text { pode descrever o assunto do } \\
\text { documento). Portanto, a partir } \\
\text { de estudos de recuperação da } \\
\text { informação do sistema, deve-se } \\
\text { optar entre linguagem natural } \\
\text { ou vocabulário controlado; }\end{array}$ & $\begin{array}{l}\text { Observa-se que a rede de bibliotecas da Unesp } \\
\text { construiu o Tesauro Unesp composto de todas as } \\
\text { áreas de assunto gerais e especializadas e poderá } \\
\text { ser utilizado pelo CEDEM para controle de } \\
\text { vocabulário e ainda participar do Grupo de } \\
\text { desenvolvimento da linguagem para inserção de } \\
\text { termos utilizado por seus usuários sem que haja } \\
\text { necessidade de construção de um vocabulário } \\
\text { controlado que demanda tempo e dedicação dos } \\
\text { profissionais; além disso todos os termos do Tesauro } \\
\text { Unesp estão descritos em registros de autoridade } \\
\text { de assunto que poderão ser compartilhados e } \\
\text { importados para dentro do SisAcervo o que } \\
\text { propiciará verificação e controle dos campos de } \\
\text { assunto nos metadados de modo automático; }\end{array}$ \\
\hline
\end{tabular}




\begin{tabular}{|l|l|l|}
\hline \multicolumn{1}{|c|}{ Variáveis } & \multicolumn{1}{|c|}{ Função } & \multicolumn{1}{c|}{ Aplicação no CEDEM } \\
\hline $\begin{array}{l}\text { Capacidade de } \\
\text { revocação e } \\
\text { precisão do } \\
\text { sistema }\end{array}$ & $\begin{array}{l}\text { Especificidade, exaustividade, } \\
\text { revocação e precisão estão } \\
\text { relacionadas. Quanto mais } \\
\text { exaustivamente um sistema } \\
\text { indexa seus documentos, maior } \\
\text { será a revocação (número de } \\
\text { documentos recuperados) na } \\
\text { busca e, inversamente } \\
\text { proporcional, a precisão será } \\
\text { menor, assim como, quanto mais } \\
\text { especificamente um sistema } \\
\text { indexa seus documentos maior } \\
\text { será a precisão. }\end{array}$ & $\begin{array}{l}\text { A exaustividade é uma variável importante que diz } \\
\text { respeito à extensão de representação do } \\
\text { conteúdo de um dado documento, ou seja, quanto } \\
\text { mais extensa for a cobertura de representação de } \\
\text { um documento por um ou mais termos gerais ou } \\
\text { específicos, mais exaustiva será a indexação e } \\
\text { maior será a revocação na recuperação. } \\
\text { Recomenda-se que a indexação seja exaustiva e } \\
\text { específica e que utilize linguagem de indexação } \\
\text { ou vocabulário controlado para calibrar a } \\
\text { capacidade de revocação e precisão do sistema } \\
\text { em função da necessidade de recuperação da } \\
\text { informação de sua comunidade de usuários. }\end{array}$ \\
\hline
\end{tabular}

Quadro 2 - Função e aplicação das variáveis do processo de indexação Fonte: Catálogo online do CEDEM

Finalmente, considera-se que um manual de indexação deva ser elaborado para o registro de todas as decisões acerca dos elementos e variáveis da indexação com a função precípua de assegurar a uniformidade das atividades de organização e representação da informação realizadas no plano horizontal da política de indexação.

\section{Considerações finais}

A política arquivística tem extraordinária relevância porque, quando falamos de documentação digital, implica questões articuladas às políticas de preservação digital para reprodução, recuperação e acesso, que são atualmente essenciais à transparência e ao imediatismo informacional. Atrelada à política arquivística está a condição sine qua non de representar para recuperar. É justamente nesse ponto que se justifica a necessidade da política de indexação, tendo em vista, a declarada razão e meta de coleções documentais originais e únicas de movimentos político-sociais custodiadas por centros de documentação serem reproduzidas digitalmente: acesso a informação e conhecimento.
Considerando-se que este estudo ensaístico teve como objetivo refletir sobre a aplicabilidade da elaboração e implementação da política de indexação no âmbito das instituições de memória no Brasil, é importante reconhecer que, certamente, os aspectos da política de indexação estão presentes nas instituições de memória, contudo, sem a devida explicitação ou organização. A partir do momento em que todos os gestores e atores envolvidos na política de informação tornam-se conscientes da existência e os reconhecem, como demonstrado no item 5 , há necessidade de sistematização das informações relativas aos planos horizontal e vertical com requisitos, elementos e variáveis. Outro ponto importante é que embora o tratamento pela indexação por assuntos seja uma etapa intermediária e raramente notada, porque está por dentro, sua sistematização e controle faz enorme diferença para quem usa o sistema de informações devido à rapidez, precisão e revocação no momento da recuperação da informação. Usar a indexação é, portanto, altamente estratégico para os objetivos das políticas arquivísticas de preservação digital que o faz para viabilizar o acesso a documentos únicos e de difícil resgate e isso, é financeiramente caro. 
A linguagem de indexação utilizada pelo sistema pode se tornar um instrumento valioso não só pela evidente função de controle de vocabulário do sistema mas para auxílio ao usuário no momento de sua busca. Além disso, dá visibilidade às áreas de assunto tratadas pelo centro de documentação.

Finalmente, no que tange à análise do sistema de informação do CEDEM reiteramos as seguintes recomendações:

- Realizar diferentes estudos para conhecimento de seus requisitos: perfil e vocabulário de domínio de seus usuários e a política institucional da Universidade para a estrutura física, financeira, material e humana do CEDEM;

- Elaborar um manual de indexação que contenha informações sobre o CEDEM e suas diversas políticas, seja arquivística, de preservação, reprodução, tratamento documental, desenvolvimento de coleções e de indexação com requisitos, elementos e variáveis e relaciona-las às especificações do SisAcervo;

- Elaborar e experimentar metodologia de avaliação para analisar problemas de recuperação, verificar ajustes na implementação da política e futuros aprimoramentos, uso do software e ferramentas de busca;

- Adotar o Tesauro Unesp como linguagem de indexação para controle do vocabulário e disponibiliza-lo junto à interface de busca do sistema de informação;

- Importar os registros de autoridade de assunto do Tesauro Unesp para o SisAcervo e obter controle de vocabulário automático nos campos de assuntos dos metadados de descrição física e temática;

- Calibrar a capacidade de revocação e precisão do sistema com exaustividade e especificidade na determinação de termos para representação dos documentos em função da necessidade de recuperação da informação de sua comunidade de usuários.

\section{Referências}

BARITÉ, M. et al. Diccionario de organización del conocimiento: clasificación, indización, terminología. 6.ed. corr.aum. Montevideo: CSIC, 2015. 212p.

BRASCHER, M., CAFÉ, L. Organização da informação ou organização do conhecimento? In: Enancib - Encontro Nacional de Pesquisa em Ciência da Informação, 2008, São Paulo. Diversidade Cultural e Políticas de Informação, 2008.

CAMARGO, Célia Reis (org.). Guia do Acervo Cedem. São Paulo: CEDEM/UNESP, 2008.

CARNEIRO, M. V. Diretrizes para uma política de indexação. R. Esc. Bibliotecon. UFMG, Belo Horizonte, v. 14, n. 2, p. 221-241, 1985.

CENTRO DE DOCUMENTAÇÃO E MEMÓRIA DA UNESP. Política de desenvolvimento de coleções e aquisição de acervos. São Paulo: CEDEM, 2015. 8fls.

CENTRO DE DOCUMENTAÇÃO E MEMÓRIA DA UNESP. I Fórum dos Centros de Documentação e Memória da Unesp. Apresentação de Solange Souza. Cedem/Unesp 30 anos - "Seminário e Fórum" Parte 4/5: dias 13 e 14 de novembro de 2017. São Paulo: CEDEM/UNESP, 2017. Disponível em: https://www.youtube.com/watch?v=xyQ8iFOfjQU. Acesso em: 18/jan/2019.

CENTRO DE DOCUMENTAÇÃO E MEMÓRIA DA UNESP. SisAcervo - Especificações Técnicas. São Paulo: s/d.

CENTRO DE DOCUMENTAÇÃO E MEMÓRIA DA UNESP. Manual de Operações: módulo cadastramento. Sistema de Acervos Permanentes da Unesp. São Paulo: Grapha Studio/CEDEM, 2013.

CENTRO DE DOCUMENTAÇÃO E MEMÓRIA DA UNESP. Relatório de Gestão 2017. São Paulo: dez/2017.

CONSELHO NACIONAL DE ARQUIVOS. Recomendações para digitalização de documentos arquivísticos permanentes. Rio de Janeiro: CONARQ, 2010.

CONSELHO NACIONAL DE ARQUIVOS. Resolução no 31 , de 28 de abril de 2010. Dispõe sobre a adoção das recomendações para digitalização de documentos arquivísticos permanentes. Diário Oficial da União, Brasília, ano CXVII, $n^{\circ} 82$, seção 1 , p. 01, 03 mai. 2010. 
CONSELHO NACIONAL DE ARQUIVOS. Câmara Técnica de Documentos Eletrônicos. Orientação Técnica $n^{\circ} 4$ - Recomendações de uso do PDF/A para documentos arquivísticos. Rio de Janeiro: CONARQ, 2016. Disponível em: http:// conarq.arquivonacional.gov.br/images/ctde/ Orientacoes/Orientacao_tecnica_4.pdfAcesso em: 18/jan/2019.

CONSELHO NACIONAL DE ARQUIVOS. NOBRA$D E$ : norma brasileira de descrição arquivística. Rio de Janeiro: Conselho Nacional de Arquivos, 2006.

CONSELHO INTERNACIONAL DE ARQUIVOS. ISAD $(g)$ : Norma geral internacional de descrição arquivística. 2. ed. rev. Rio de Janeiro: Arquivo Nacional, 2000.

FOSKET, A. C. A abordagem temática da informação. São Paulo: Polígono, 1973.

FUJITA, M. S. L. A política de indexação para representação e recuperação da informação. In: GIL LEIVA, I., FUJITA, M. S. L. (Eds.) Política de indexação. São Paulo: Cultura Acadêmica; Marília: Oficina Universitária, 2012. p.17-30. Disponível em: http://ebooks.marilia.unesp.br/ index.php/lab_editorial/catalog/book/32. Acesso em: $30 /$ jan/2019

FUJITA, M. S. L.; TROITIÑO, S. Política de indexação em arquivos de instituições de saúde. Inf. Pauta, Fortaleza, v.3, número especial, p.95-116, nov.2018. Disponível em: http://www.periodicos. ufc.br/informacaoempauta/issue/view/Sinforgeds\%202018/showToc . Acesso em: 30/jan/2019.

FUSTER RUIZ, Francisco. Política archivística e planificación general de los archivos. In: RUIZ RODRÍGUEZ, Antonio Ángel (ed.). Manual de Archivística. Madrid: Editorial Sintesis, 1995. p. 281-324.

INTERNATIONAL COUNCIL ON ARCHIVES. ISAAR(CPF): International Standard Archival Authority Record for Corporate Bodies, Persons and Families. 2. ed., Paris: ICA, 2004.

INTERNATIONAL STANDARD ORGANIZATION. 19005-1. Document management - Electronic document fi le format for long-term preservation - Use of PDF 1.4 (PDF/A-1). International Organization for Standardization, 2005.

INTERNATIONAL STANDARD ORGANIZATION. 15489: Information and Documentation - Record Management - Part 1: Guidelines [Technical Report] (2001). Ginebra, Suiza: ISO, 2001.
LANCASTER, F. W. Information retrieval systems: characteristics, testing and evaluation. New York: John Wiley \& Sons, 1968.

ORTEGA, C. D. Fundamentos da organização da informação frente à produção de documentos. Transinformação, v. 20, p. 1, 2008.

SCOTT, Peter. The record group concept: a case for abandonment. The American Archivist, [S.I.], v. 29, n. 4, p. 493-504, out. 1966. Doi: http://dx.doi. org/10.17723/aarc.29.4.y886054240174401.

SOUSA, Renato Tarcisio Barbosa de. O arquivista e as políticas públicas de arquivo. In: CONGRESSO NACIONAL DE ARQUIVOLOGIA, 2., 2006, Porto Alegre. Anais. Porto Alegre: ABARQ/UnB, 2006.

UNIVERSIDADE ESTADUAL PAULISTA JÚLIO DE MESQUITA FILHO. Processo RUNESP $n^{\circ}$ 595/1987 - Grupo de Trabalho para a Preservação de Documentos e Memória Histórica da Unesp. São Paulo:UNESP, 1987. 2v.

VÁSQUEZ MURILLO, Manuel. Hacia una política archivística. In: NAVARRO, Ana Célia. Archivos y documentos: textos seminales. SP: ARQ-SP, 2015.

\section{Recebido em 01/02/2019 Aprovado em 05/02/2019}

I Mariângela Spotti Lopes Fugita. Professora do Programa de Pós-Graduação em Ciência da Informação da Universidade Estadual Paulista Júlio de Mesquita Filho, UNESP, Brasil. Contato: mariangela.fugita@unesp.br

Il Sonia Troitiño. Professora do Programa de Pós-Graduação em Ciência da Informação da Universidade Estadual Paulista Júlio de Mesquita Filho, UNESP, Brasil. Contato: sonia.troitino@unesp.br

III Disponível em https://sistemas.unesp.br/cedem/publico/material.pesquisar.action 